Full length article

\title{
Infection levels and species diversity of ascaridoid nematodes in Atlantic cod, Gadus morhua, are correlated with geographic area and fish size
}

\author{
M. Gay ${ }^{\mathrm{a}, *}$, M. Bao ${ }^{\mathrm{b}}$, K. MacKenzie ${ }^{\mathrm{b}}$, S. Pascual ${ }^{\mathrm{c}}, \mathrm{K}$. Buchmann ${ }^{\mathrm{d}}$, O. Bourgau ${ }^{\mathrm{a}}$, C. Couvreur ${ }^{\mathrm{a}}$, \\ S. Mattiucci ${ }^{\mathrm{e}}$, M. Paoletti ${ }^{\mathrm{e}, \mathrm{f}}$, L.C. Hastie ${ }^{\mathrm{b}}$, A. Levsen ${ }^{g}$, G.J. Pierce ${ }^{\mathrm{b}, \mathrm{c}, \mathrm{h}}$

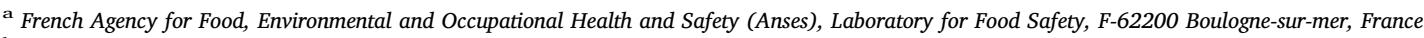 \\ b Oceanlab, University of Aberdeen, Main Street, Newburgh, Aberdeenshire, AB41 6AA, UK \\ c Instituto de Investigaciones Marinas (CSIC), Eduardo Cabello 6, 36208, Vigo, Spain \\ ${ }^{\mathrm{d}}$ Faculty of Health and Medical Sciences, University of Copenhagen, Copenhagen, Denmark \\ e Department of Public Health and Infectious Diseases, Section of Parasitology, Sapienza-University of Rome, P.le Aldo Moro, 5, 00185, Rome, Italy \\ ${ }^{\mathrm{f}}$ Department of Ecological and Biological Sciences Tuscia University, Largo dell'Università s.n.c., 01100, Viterbo, Italy \\ ${ }^{g}$ National Institute of Nutrition and Seafood Research (NIFES), PO Box 2029 Nordnes, N-5817 Bergen, Norway

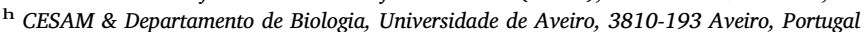

\section{A R T I C L E I N F O}

\section{Keywords:}

Anisakis

Zoonotic nematodes

Seafood safety

Distribution in fillets

Molecular identification

\begin{abstract}
A B S T R A C T
Atlantic cod (Gadus morhua) is among the most important commercial fish species on the world market. Its infection by ascaridoid nematodes has long been known, Pseudoterranova even being named cod worm. In the present study, 755 individuals were sampled in the Barents, Baltic and North Seas during 2012-2014.

Prevalences for Anisakis in whole fish and in fillets in the different fishing areas varied from 16 to $100 \%$ and from 12 to $90 \%$ respectively. Abundance was also greatly influenced by the sampling area. Generalized additive model results indicate higher numbers of Anisakis in the North Sea, even after the larger body size was accounted for. Numbers and prevalence of Anisakis were positively related to fish length or weight. The prevalence of parasites in whole fish and in fillets was also influenced by the season, with the spring displaying a peak for the prevalence in whole fish and, at the same time, a drop for the prevalence in fillets. Whereas $46 \%$ of cod had Anisakis larvae in their fillets, the majority (39\%) had parasites mainly in the ventral part of the fillet and only $12 \%$ had parasites in their dorsal part. This observation is of importance for the processing of the fish. Indeed, the trimming of the ventral part of the cod fillet would allow the almost total elimination of ascaridoids except for cod from the Baltic Sea where there was no difference between the dorsal and the ventral part.

The presence of other ascaridoid genera was also noticeable in some areas. For Pseudoterranova, the highest prevalence $(45 \%)$ in whole fish was observed in the Northern North Sea, whereas the other areas had prevalences between 3 and 16\%. Contracaecum was present in every commercial size cod sampled in the Baltic Sea with an intensity of up to 96 worms but no Contracaecum was isolated from the Central North Sea. Non-zoonotic Hysterothylacium was absent from the Baltic Sea but with a prevalence of $83 \%$ in the Barents and the Northern North Sea.

A subsample of worms was identified with genetic-molecular tools and assigned to the species A. simplex (s.s.), A. pegreffii, $P$. decipiens (s.s.), P. krabbei, C. osculatum and H. aduncum. In addition to high prevalence and abundance values, the cod sampled in this study presented a diversity of ascaridoid nematodes with a majority of fish displaying a co-infection. Out of 295 whole infected fish, 269 were co-infected by at least 2 genera.
\end{abstract}

\section{Introduction}

Atlantic cod (Gadus morhua) is among the most important commercial fish species on the world market. In 2012, FAO reported that this species was amongst the 10 most fished species in the world, with about 200,000 tons fished per year in 2010 and 2011. It occurs in shelf waters throughout the North Atlantic Ocean. In Europe, it has been recorded from the North Western Iberian Peninsula to the Barents Sea, including British and Icelandic waters as well as some brackish water localities in the Baltic Sea (Bañon et al., 2010; ICES, 2005). From a biological point of view, this species, due to its large maximum length, is almost at the top of the food chain, playing an important role in

\footnotetext{
* Corresponding author

E-mail address: melanie.gay@anses.fr (M. Gay).
} 
ecosystems, although reduction in abundance due to fishing has reduced its trophic role (Link et al., 2009). Its feeding behavior evolves with its size, the diet shifting from small invertebrates in young cod to a wide variety of fish - including cannibalism - in larger individuals (Münster et al., 2015).

It may be marketed fresh, chilled, frozen or processed (salted, dried, smoked, etc.), either whole or in fillets. Besides the consumption of its flesh, many products are also derived from other organs such as liver or gonads (liver oil, frozen or smoked roes).

Ascaridoid nematodes have been described in a wide variety of fish hosts all over the world (Mattiucci et al., 2015). The most frequently encountered genera are zoonotic Anisakis, Pseudoterranova, Contracaecum and non-zoonotic Hysterothylacium. The life cycles of the different genera are broadly similar, with different definitive hosts, such as cetaceans, pinnipeds, piscivorous birds and piscivorous fish (Cavallero et al., 2011; Klimpel et al., 2004; Køie and Fagerholm, 1995). Depending on the geographical areas, suitable intermediate hosts may occur more or less abundantly and may still be unknown (Klimpel et al., 2004). Eggs are released with the final host faeces and lead to free swimming ensheathed larvae in the marine environment. The larvae undergo one or two moults before being ingested by invertebrates, mostly small crustaceans. These intermediate hosts are then eaten by a wide variety of transport or paratenic hosts, including cephalopods and fish. At this stage, many different life-cycle patterns may be observed (EFSA, 2010). The fish may be directly eaten by the definitive host and the larva moults to give the adult form of the parasite. The fish may be eaten by another fish, in which case the larvae may be freed from the first paratenic host in the second host's digestive tract and then re-encapsulate in this new host (Køie and Fagerholm, 1995; Zuo et al., 2016). This phenomenon may occur several times, inducing an accumulation of ascaridoid larvae along the trophic web (Münster et al., 2015; Zuo et al., 2016). Moreover, the behavior of the larvae may be different depending on several factors, some still unknown: in some cases, most parasites will remain in the visceral cavity of the fish or within the visceral organs, whereas in other cases, parasites will migrate to the musculature of the fish (Cipriani et al., 2016 and references therein).

The presence of parasites in the edible part of the fish represents a threat to public health, since these parasites are responsible for digestive and/or allergic pathologies (Audicana and Kennedy, 2008). Moreover, it is an aesthetic problem, inducing rejection from consumers and imposing an important economic burden on the stakeholders who need to check the products (Abollo et al., 2001). Recently, Bao et al. (2017) described the avoidance of fish by some Spanish consumers due to the potential presence of anisakids.

The infection of the different species of gadoids, including Gadus morhua, by ascaridoid nematodes is well-documented in many parts of the world, including the Western Atlantic Ocean (Brattey and Bishop, 1992), the Pacific Ocean (Quiazon et al., 2011), the Baltic Sea (Horbowy et al., 2016; Mehrdana et al., 2014), the Norwegian Sea
(Hemmingsen et al., 1993), the Irish and Celtic Seas (Perdiguero-Alonso et al., 2008). Perdiguero-Alonso et al. (2008) described the variation in macroparasite fauna in cod in 6 distinct geographical areas from the North-East Atlantic Ocean (the Baltic, Celtic, Irish and North seas, Icelandic waters and the Trondheim fjord). As for Anisakis spp. larvae, they found prevalences between 5 and $99.4 \%$. The purpose of the study from Perdiguero-Alonso et al. (2008) was more to evaluate the richness and abundance of the parasite fauna than to look into details of the distribution for the different parasites groups. Thus, these authors did not discuss about the factors influencing these variations specifically for ascaridoid nematodes. It is necessary to account for effects of potential confounding variables, e.g. fish size (Zuo et al., 2016), sex, and condition, as well as season and year. Indeed, one could hypothesize that older, larger fish will have ingested a higher number of parasites and that fish size would reflect the intensity of infection. However, the relationship between condition and parasite burden is more complex. A positive relationship might be expected if good condition indicates higher feeding intensity and hence greater parasite ingestion and the ascaridoids will contribute to measured body weight, whereas an important parasite burden may induce a weaker condition factor (Lagrue and Poulin, 2015; Mehrdana et al., 2014; Pulleiro-Potel et al., 2015). Moreover, some fish show immunological responses to ascaridoids potentially inducing a reduction in the parasite burden (Bahlool et al., 2012; Levsen et al., 2017a,b).

The present work was a part of an epidemiological survey included in the EU FP7 PARASITE project (GA no. 312068; Levsen et al., $2017 \mathrm{a}, \mathrm{b})$. Its intention was to explore the presence, intensity and distribution of the different genera of ascaridoid nematodes in G. morhua from different regions of the Eastern Atlantic Ocean in order to evaluate variability in infestation frequency and intensity, and reasons for this variation. An additional aim was to describe the distribution of these parasites in the different organs of the fish.

\section{Material and methods}

\subsection{Sampling and parasite detection}

A total of 755 Atlantic cod (Gadus morhua) was sampled between November 2012 and November 2014 in the North Sea (ICES areas IV-a and IV-b), in the Barents Sea (ICES area I-b) and in the Baltic Sea (ICES area III-d). Fish were sampled either on board during scientific cruises or commercial fishing, or bought on land from fishermen.

Each fish was measured (total, fork and standard lengths), weighed and when possible its sex was recorded. Fish host biometric data are shown in Table 1. The liver and gonad weights as well as the stomach contents were recorded when possible. Ascaridoid parasites were obtained by the UV-press method for fish sampled in the North and Barents Seas (Karl and Leinemann, 1993; Karl and Levsen, 2011) or by artificial digestion for fish sampled in the Baltic Sea (Llarena-Reino et al., 2013) due to the absence of press at this location. Both right and

Table 1

Geographical origin, Biometric data of cod batches, including length and weight indicated as mean \pm SD (range).

\begin{tabular}{|c|c|c|c|c|c|c|c|c|c|}
\hline Batch & $\mathrm{Nb}$ analyzed ${ }^{\mathrm{a}}$ & Fishing date & Origin & Lab & Geographical origin & Total length (mm) & Weight (g) & $\begin{array}{l}\text { Trading } \\
\text { calibre }\end{array}$ & $\begin{array}{l}\text { Parasite detection } \\
\text { methods }\end{array}$ \\
\hline 1 & 103 & $\begin{array}{l}\text { Aug 2013-Aug } \\
2014\end{array}$ & $\begin{array}{l}\text { Scientific } \\
\text { campaign }\end{array}$ & $\begin{array}{l}\text { Univ. } \\
\text { Aberdeen }\end{array}$ & $\begin{array}{l}\text { Central North Sea } \\
\text { (IV.b) }\end{array}$ & $\begin{array}{l}222.90 \pm 169.20 \\
(80-950)\end{array}$ & $\begin{array}{l}388.60 \pm 965.30 \\
(5-5330)\end{array}$ & $\begin{array}{l}\mathrm{B}^{\mathrm{b}} \\
4-5\end{array}$ & $\begin{array}{l}\text { Dissection and } \\
\text { UV-press }\end{array}$ \\
\hline 2 & 120 & Nov 2013 & $\begin{array}{l}\text { Commercial } \\
\text { fisherman }\end{array}$ & Anses & $\begin{array}{l}\text { Northern North Sea } \\
\text { (IV.a) }\end{array}$ & $\begin{array}{l}749.60 \pm 143.34 \\
(515-1100)\end{array}$ & $\begin{array}{l}5004.20 \pm 2836.24 \\
(1592-17600)\end{array}$ & $1-4$ & $\begin{array}{l}\text { Dissection and } \\
\text { UV-press }\end{array}$ \\
\hline 3 & $\begin{array}{l}146 \\
(46)\end{array}$ & $\begin{array}{l}\text { Nov 2013-Nov } \\
2014\end{array}$ & $\begin{array}{l}\text { Commercial } \\
\text { fisherman }\end{array}$ & Hermes & $\begin{array}{l}\text { Barents Sea } \\
\text { (I) }\end{array}$ & $\begin{array}{l}661.03 \pm 91.18 \\
(450-850)\end{array}$ & $\begin{array}{l}2692.60 \pm 1109.77 \\
(960-5540)\end{array}$ & $2-5$ & $\begin{array}{l}\text { Dissection and } \\
\text { UV-press }\end{array}$ \\
\hline 4 & $\begin{array}{l}386 \\
(188)\end{array}$ & $\begin{array}{l}\text { Nov 2012-Nov } \\
2014\end{array}$ & $\begin{array}{l}\text { Scientific } \\
\text { campaign }\end{array}$ & $\mathrm{UCPH}$ & $\begin{array}{l}\text { Baltic Sea } \\
\text { (III) }\end{array}$ & $\begin{array}{l}356.50 \pm 192.80 \\
(54-810)\end{array}$ & $\begin{array}{l}605.30 \pm 655.00 \\
(0.7-3793)\end{array}$ & $\begin{array}{l}\mathrm{B}^{\mathrm{b}} \\
3-5\end{array}$ & Artificial digestion \\
\hline
\end{tabular}

\footnotetext{
${ }^{a}$ Number in parenthesis are number of eviscerated fish.
}

${ }^{\mathrm{b}} \mathrm{B}$ means below trading caliber. 


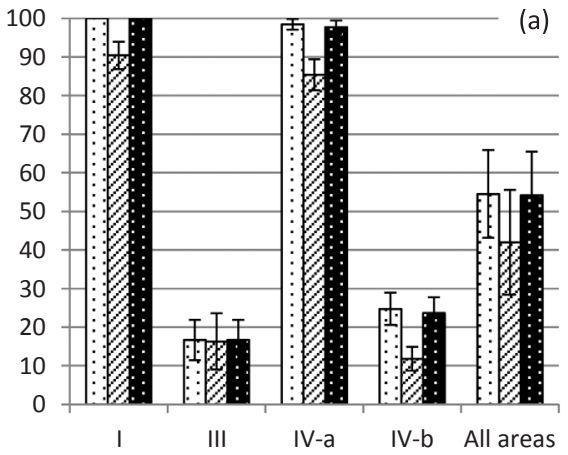

(a)

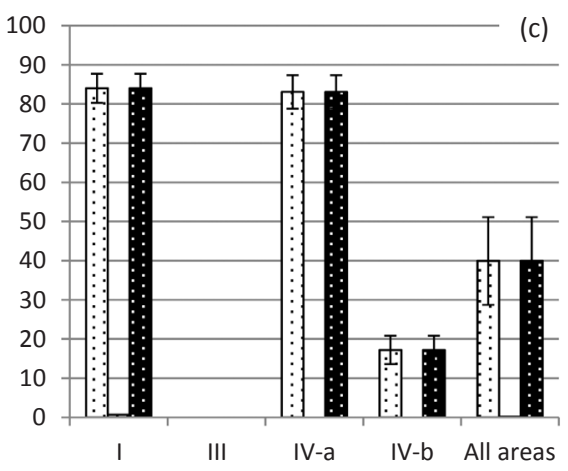

(c)

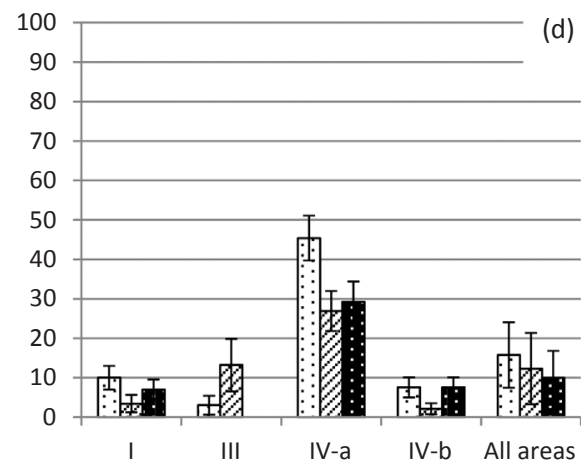

Fig. 1. Prevalence by geographical area for Anisakis (a), Contracaecum (b), Hysterothylacium (c), Pseudoterranova

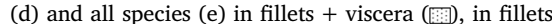

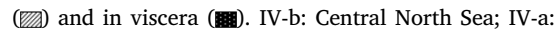
Northern North Sea; I: Barents Sea; III: Baltic Sea; All: all areas included. Error scale $=$ SD.

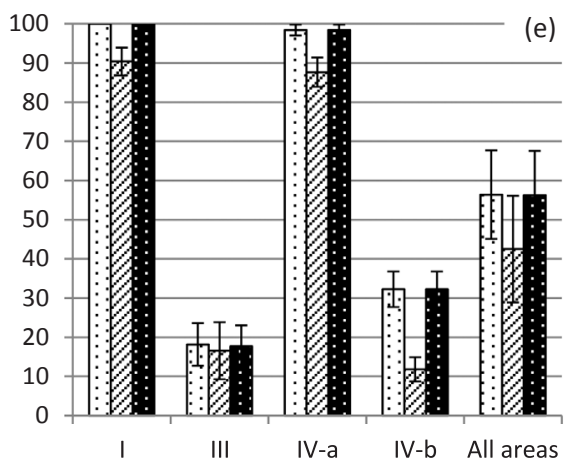

left side fillets were divided into four parts: anterior ventral (or belly flaps), anterior dorsal, posterior ventral and posterior dorsal. The precise infection site of the parasites within the different organs was recorded. Out of the 755 fish sampled, 46 from the Barents Sea and 188 from the Baltic Sea had been eviscerated prior to analysis and were thus excluded from the parts of the results dealing with overall and visceral presence and abundance of parasites. Thus, for analyses dealing with presence and abundance in fillets, the whole sampling was included, whereas for analyses dealing with presence and abundance in whole fish and viscera, only 521 fish were included.

\subsection{Parasitological descriptors}

Different descriptors of the parasite distribution used in the present study rely on the definitions from Bush et al. (1997). In particular, prevalence is "the number of hosts infected with one or more individuals of a parasite species (or of a taxonomic group) divided by the number of hosts examined for that parasite species". The abundance is "the number of individuals of a particular parasite in/on a single host regardless of whether or not the host is infected". The intensity (of infection) is "the number of individuals of a particular parasite species in a single infected host".

\subsection{Parasite identification}

Each recovered parasite was presumptively identified morphologically either by their fluorescence under UV-light or under a dissecting microscope to the genus level (Berland, 1961, 1991; Smith and Wootten, 1984a,b,c).

A subsample of parasites from different origins was molecularly identified. The DNA of each individual parasite was extracted using Wizard ${ }^{\circ}$ Genomic DNA Purification Kit (Promega) following manufacturer's instructions after grinding of the parasite with a sterile piston pellet. DNA was kept at $-20^{\circ} \mathrm{C}$ until used.

The mitochondrial cytochrome c oxidase subunit II ( $\operatorname{cox} 2)$ gene was amplified using the primers $211 \mathrm{~F}$ ( $5^{\prime}$-TTT TCT AGT TAT ATA GAT TGR TTY AT-3') and $210 \mathrm{R}$ (5'-CAC CAA CTC TTA AAA TTA TC-3') (Nadler and Hudspeth, 2000) which span the mtDNA nucleotide positions 10,639-11,248 as defined in Ascaris suum [GenBank X54253]. PCR was carried out under the following conditions: $94^{\circ} \mathrm{C}$ for $3 \mathrm{~min}$ (initial denaturation) followed by 34 cycles at $94^{\circ} \mathrm{C}$ for $30 \mathrm{~s}$ (denaturation), $46^{\circ} \mathrm{C}$ for $60 \mathrm{~s}$ (annealing) and $72^{\circ} \mathrm{C}$ for $90 \mathrm{~s}$ (extension) prior to post amplification at $72{ }^{\circ} \mathrm{C}$ for $10 \mathrm{~min}$ (Valentini et al., 2006). The obtained sequences were analyzed by GenBank Blast software and subsequently aligned with available cox 2 rDNA sequences for members of Anisakidae and Raphidascarididae by ClustalX (Altschul et al., 1997). 

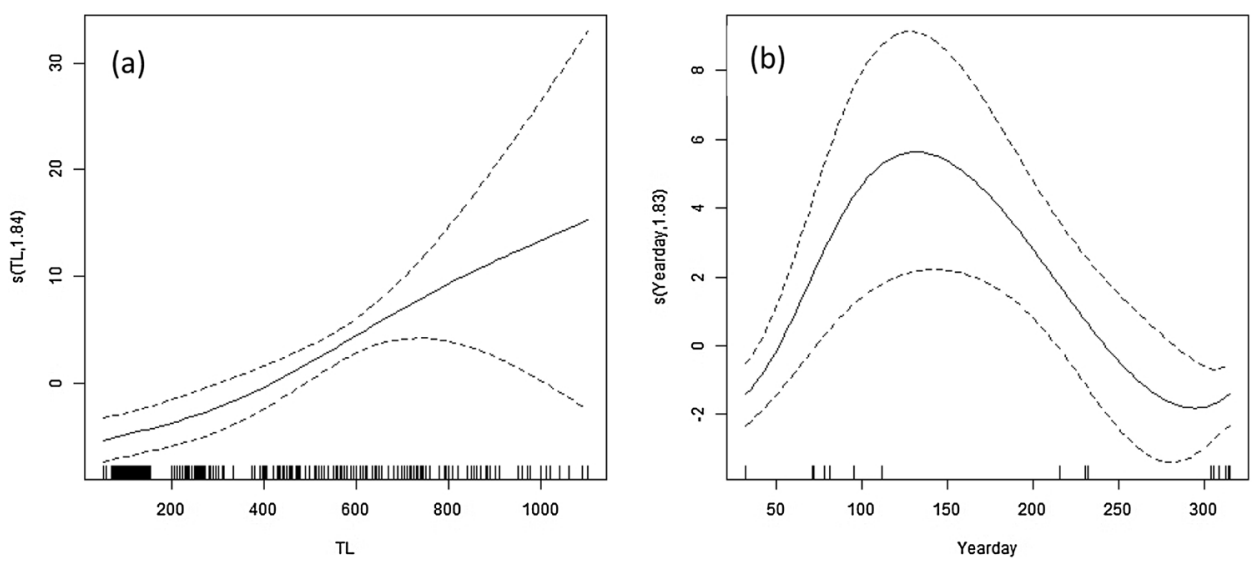

Fig. 2. GAM smoothing curves fitted to partial effect of explanatory variables on the presence of Anisakis in fillets + viscera ((a) total length and (b) day of year) and in fillets ((c) total length and (d) day of year). Smoothers are shown only for continuous variables with significant effects. Dashed lines represent 95\% confidence intervals around the main effects. Note that Barents Sea samples were excluded from the statistical analysis for fillets + viscera as Anisakis was always present, which precluded testing for regional variation.TL: total length of fish; Yearday: day of sampling (from 1 for the 1st of January to 365 for the 31st of December).
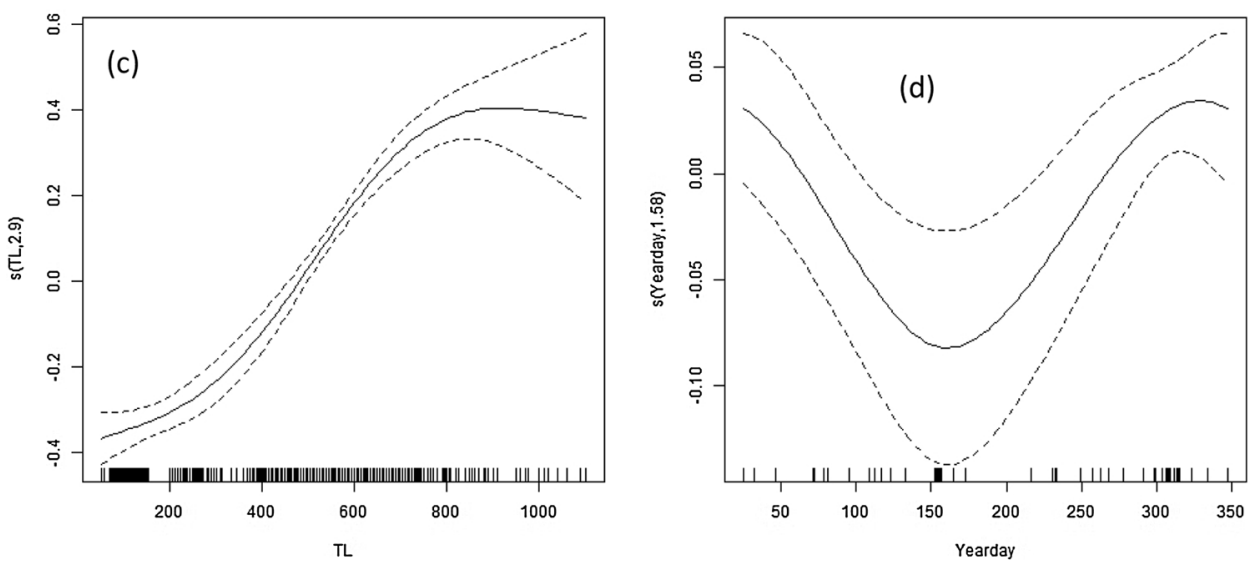

\subsection{Statistical analysis}

All data (fishing area, date, fish species and biometric data, parasitological examinations) were entered into MS Excel worksheets and the PARASITE BioBank database by the different partners involved and then assembled and analyzed by one partner. Initial data screening was carried out to identify and if possible correct (or else remove) erroneous or implausible data. The whole set of data was included to the statistical analysis, meaning 755 fish for analyses on fillets and 521 for analyses on whole fish or viscera.

Log-transformation of total length and weight achieved an approximately linear relationship between these variables. In addition, sampling area had a strong effect on total weight $(\mathrm{p}<0.001)$. Thus the variable "Residual weight" was established by accounting for the influence of length and area on the weight, by fitting a generalized additive models (GAM) and extracting the residuals so as to evaluate the influence of the adjusted weight on the presence and abundance of ascaridoids in cod. The fitted model was:

$\log (\mathrm{TW}) \sim 1+$ as.factor(Area_code) $+\mathrm{s}(\log (\mathrm{TL}), \mathrm{k}=4)$,

with TW the total weight of individual fish, TL the total length of individual fish, Area_code the fishing area (ICES names),

This model explained $99.6 \%$ of deviance in $\log$ (TW) $(\mathrm{P}<0.0001$ for both variables); $\log \mathrm{TL}$ alone explained $99.5 \%$. Adding month or year-day to the model produced no significant improvement. The "residual weight" variable may also be viewed as a condition index from which the influence of area has been removed.

A first set of GAM analyses was carried out including the total length of the fish, the condition factor, the sampling date (expressed as year and day of the year) and the geographical area as explanatory variables. Sex was excluded from the whole analysis due the lack of data for numerous individuals. The geographical area was defined based on the
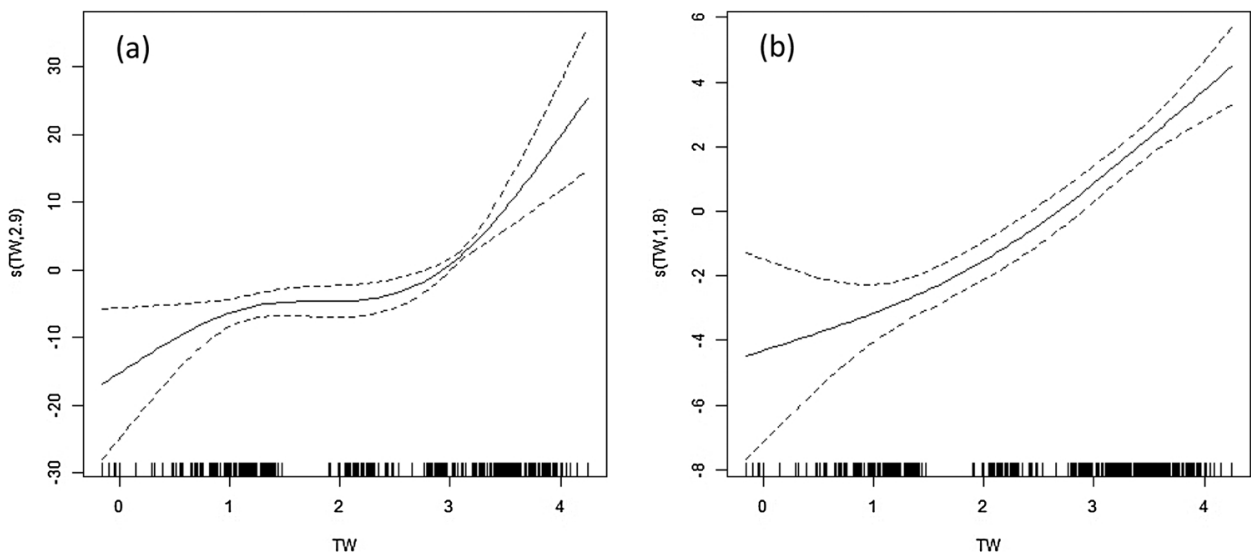

Fig. 3. GAM smoothing curves fitted to partial effect of explanatory variables including log transformed total weight on the presence of Anisakis in fillets + viscera ((a) total weight) and in fillets ((b) total weight). Smoothers are shown only for continuous variables with significant effects. Dashed lines represent $95 \%$ confidence intervals around the main effects. TW: total weight of the fish. 


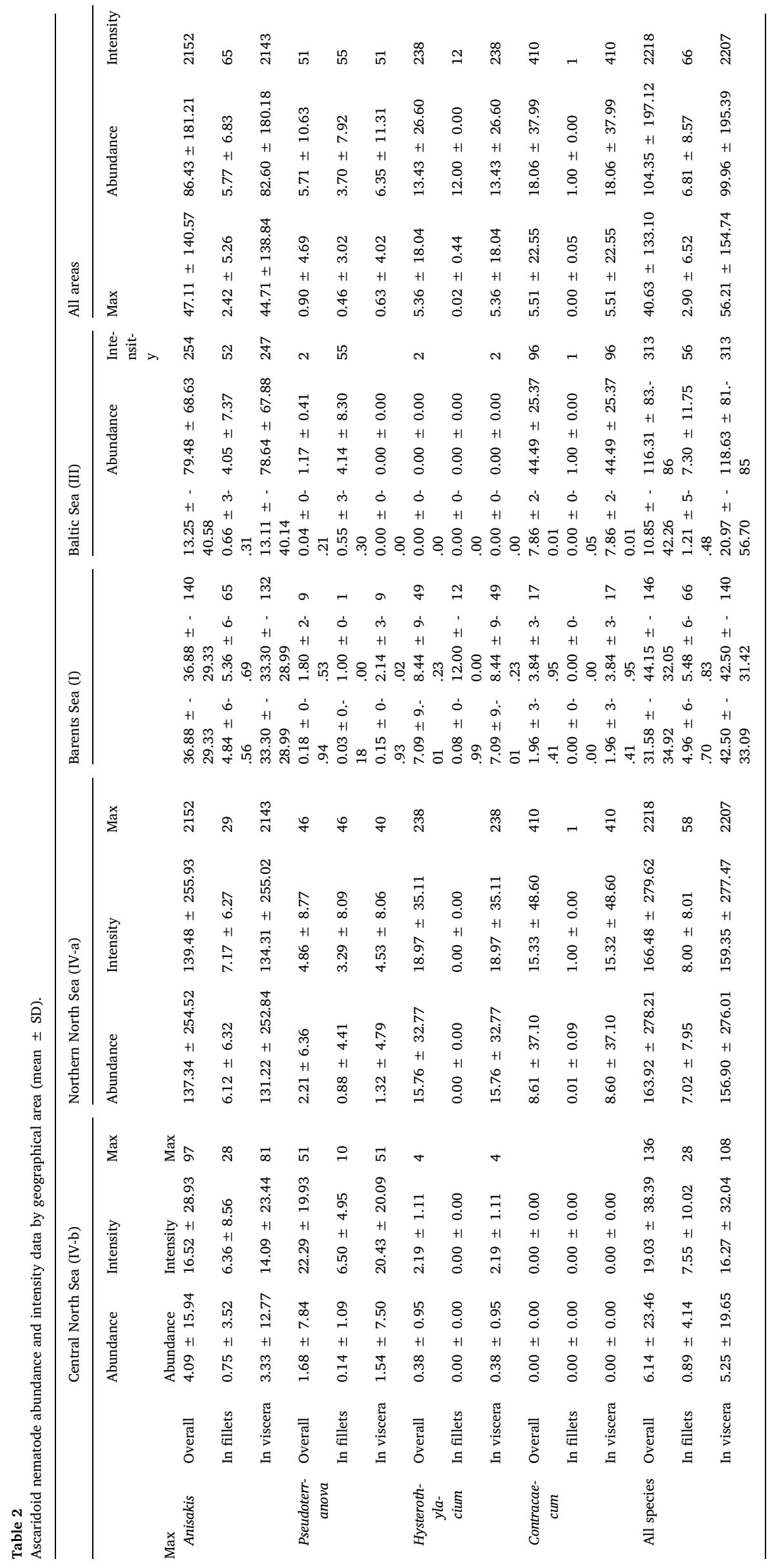


(a)

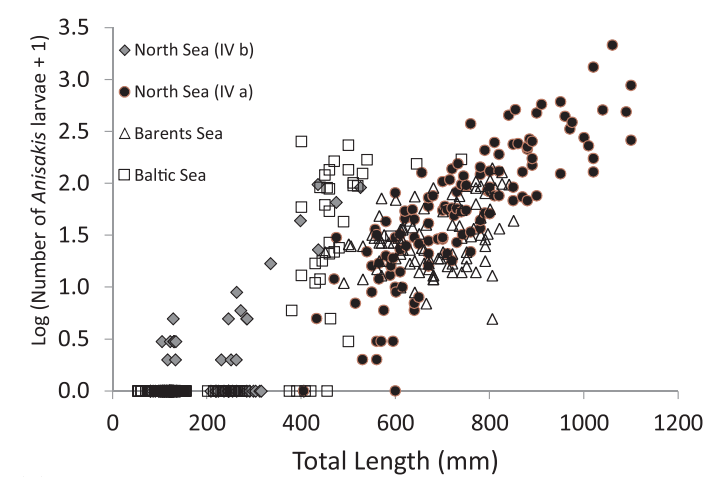

(c)

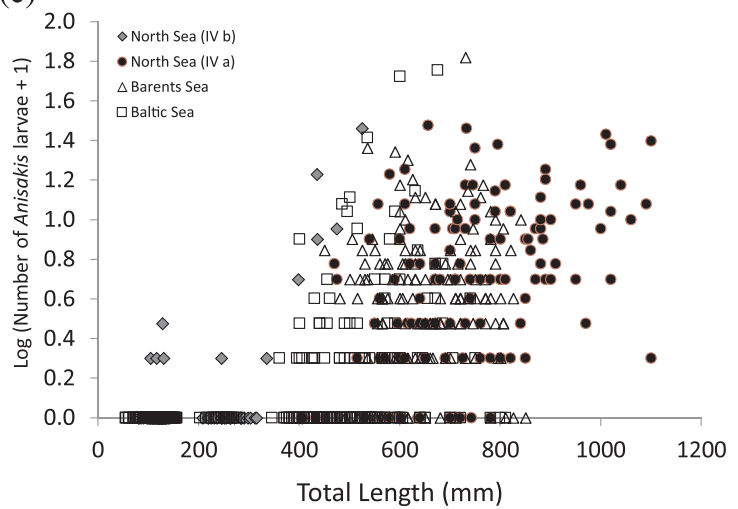

(b)

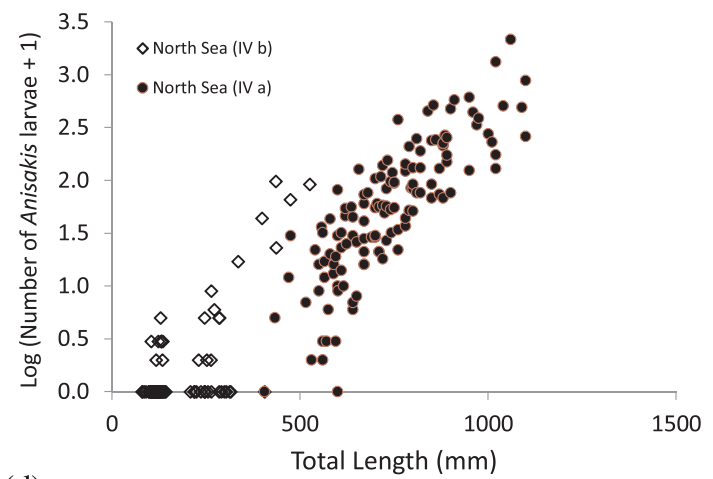

(d)

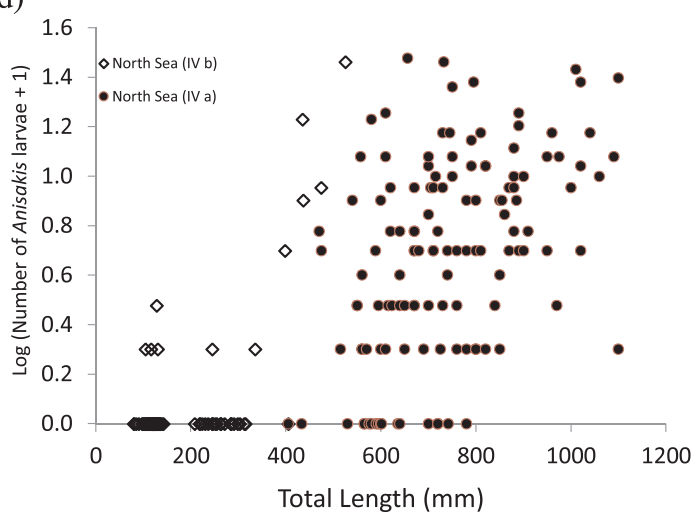

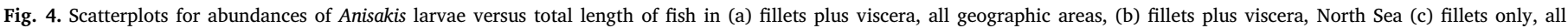
geographic areas and (d) fillets only, North Sea (TL = total length of the fish in mm; Anisakis: number of Anisakis larvae; An_Musc = number of Anisakis larvae in fillets).

ICES zones, namely I (Barents Sea), III (Baltic Sea), IVa (northern North Sea) and IVb (Central North Sea). However, areas IVa and IVb were combined since they were sampled in different seasons. Smoothers were fitted to continuous variables, constraining the number of knots $(\mathrm{k}=4)$ to avoid overfitting and to restrict the smoothers to simple, biologically realistic, forms. In addition, day of year was treated as a circular variable by fitting a cyclic cubic spline.

A second set of GAM analyses was carried out including the total weight (log-transformed to avoid undue influence from the relatively small number of very large fish) instead of the total length. A variation of this analysis took into account the weight as classes instead of a continuous variable. The weight classes were defined according to the EU regulation 2406/96: fish above $7 \mathrm{~kg}$, between 4 and $7 \mathrm{~kg}$, between 2 and $4 \mathrm{~kg}$, between 1 and $2 \mathrm{~kg}$, between $300 \mathrm{~g}$ and $1 \mathrm{~kg}$ or below $300 \mathrm{~g}$ and the results with reference to these weight categories were described.

\section{Results}

\subsection{Anisakis infection data}

\subsubsection{Prevalence values in whole fish}

The prevalence of Anisakis larvae in the different batches of fish as well as the different infection site within the fish was highly variable (Fig. 1). The overall prevalence for Anisakis larvae for the 521 fish analyzed whole, all organs and all geographical areas included was $54 \%$.

Given the $100 \%$ prevalence observed for the Barents Sea samples, this geographical area was excluded from this statistical analysis. The final model (with lowest AIC, $80.1 \%$ of deviance explained) contained effects of total length $(P<0.0001$, Fig. 2a), day of year $(P=0.0013$,
Fig. 2b) and a marginally non-significant effect of area $(P=0.071)$. It is noticeable that fish from the Baltic Sea were smaller than the other fish sampled but this difference is accounted for in the models - all effects described are partial effects, accounting for effects of other explanatory variables included in the model.

Further GAMs were fitted using log-transformed total weight instead of the (untransformed) total length. The final model for whole fish (deviance explained $=81.1 \%$ ) included effects of day of year with a similar effect as for the length model and of weight (Fig. 3a), although the trend was not evident for fish in the smallest and largest commercial categories as defined in the EU regulation 2406/96.

\subsubsection{Prevalence in fillets}

The final model (deviance explained $=57.1 \%$ ) included effects of total length $(\mathrm{P}<0.001$, Fig. $2 \mathrm{c})$, area $(\mathrm{P}<0.0001)$ and day of year $(\mathrm{P}=0.0038)$. Prevalence, in contrast to results for whole fish, tended to be lower in the middle of the year (Fig. 2d).

The final model for prevalence of Anisakis larvae in fish muscle (deviance explained $=63.6 \%)$ included effects of weight $(\mathrm{P}<0.0001)$ and geographical area (Fig. 3b) although again the trend was not apparent in the largest and smallest fish (in this case in fish in the largest size class and fish in the lower range of sizes within the smallest size class).

\subsubsection{Abundance and intensity values in whole fish}

The abundance of Anisakis larvae in whole fish generally followed similar trends as the prevalence of Anisakis (Table 2). A general increase of Anisakis abundances was observed with increasing length (Fig. 4a). A relatively high Anisakis numbers compared to the relatively small size of some Baltic cod was also noticed.

The final GAM for Anisakis numbers in fillets and viscera combined 
(deviance explained $=85.6 \%, \mathrm{~N}=512$ ) included effects of length, day of year, residual weight and area (all $\mathrm{P}<0.001$, Fig. 5a-c).

When the log-transformed total weight was used as a variable instead of the total length for the GAM analysis, the final model for numbers of Anisakis in whole fish (deviance explained $=84.6 \%$ ) was fairly similar to the previous model, with effects of weight, day of year and area (all $\mathrm{P}<0.0001$, Fig. 6aand b).

\subsubsection{Abundance and intensity values in fillets}

The abundance of Anisakis larvae in fillets generally followed similar trends as the prevalence of Anisakis in fillets (Table 2), but somewhat different from the abundance of Anisakis in whole fish (Fig. 4c, d). Whereas only fish above $70 \mathrm{~cm}$ had more than 300 Anisakis, intensities of Anisakis in the fillets greater than 10 were observed starting from fish above $40 \mathrm{cms}$ in total length.
The final GAM for numbers of Anisakis in muscle (deviance explained $=55.9 \%$ ) included effects of length, day of year and area (all $\mathrm{P}<0.0001$, Fig. 5d and e).

The model for Anisakis abundance in muscle (deviance explained $=67.1 \%)$ included effects of weight $(\mathrm{P}<0.0001)$ and area $(\mathrm{P}=0.0009$, Fig. 6c).

\subsection{Parasitic infection values for other genera}

GAM analyses were also run for all ascaridoid instead of only Anisakis (data not shown). For prevalence of all ascaridoid in viscera + fillets, the model was similar to the Anisakis model (deviance explained $76 \%$ ), but the area effect was not significant.

For presence of all ascaridoid in fillets, the sampling area and the total length of fish effects persisted, much as for Anisakis, but the
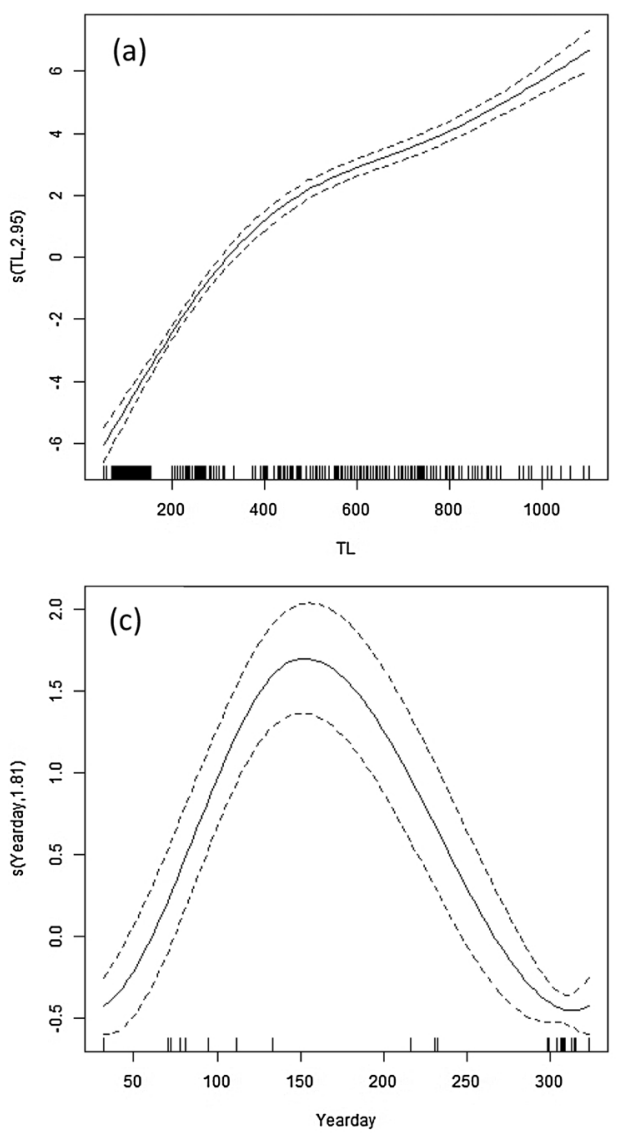
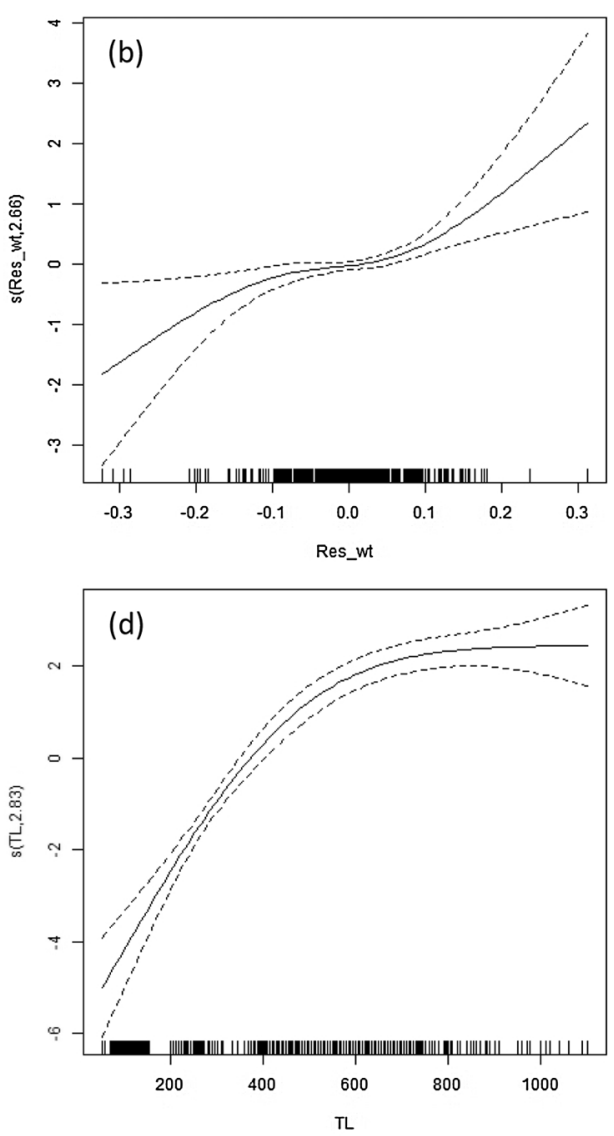

Fig. 5. GAM smoothing curves fitted to partial effect of explanatory variables on the abundance of Anisakis in fillets + viscera ((a) total length; (b) residual weight and (c) day of year) and in fillets ((d) total length and (e) day of year). Smoothers are shown only for continuous variables with significant effects. Dashed lines represent 95\% confidence intervals around the main effects. TL: total length of fish; Res_wt: residual weight equivalent to a condition factor from which the influence of area has been removed; Yearday: day of sampling (from 1 for the 1st of January to 365 for the 31st of December).

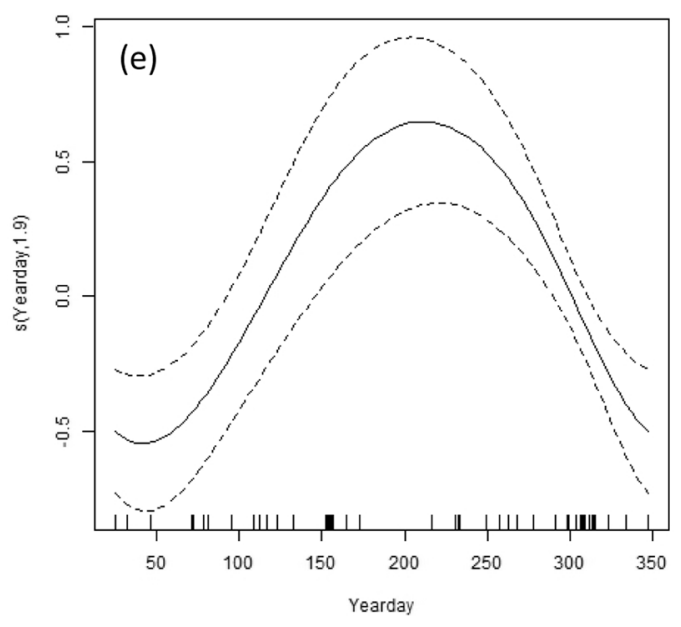



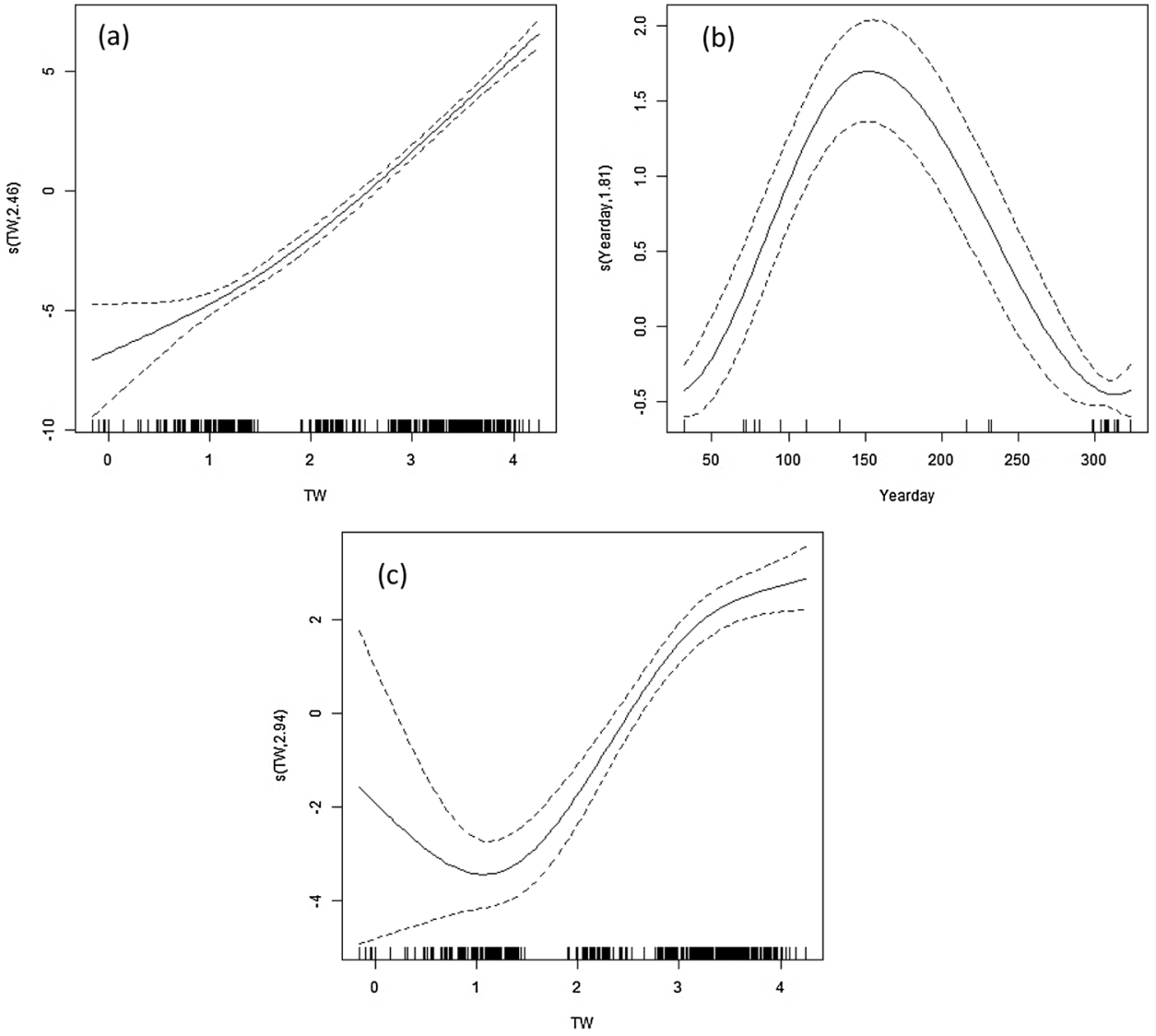

seasonal effect disappeared. Over all, the percentage of deviance explained was $51.9 \%$. As for the abundance of all ascaridoid in viscera + fillets and in viscera only, using total length of fish as an explanatory variable, the models were almost identical to those for Anisakis only, with the same patterns and trends.

The vast majority of fish were co-infected by at least 2 genera. Out of 295 whole infected fish, 269 were co-infected by at least 2 genera.

\subsubsection{Pseudoterranova spp.}

The prevalences of Pseudoterranova larvae for the 521 whole fish were respectively 16 and $10 \%$ for overall fish and viscera and $12 \%$ in the fillets for the 755 analyzed fish (Fig. 1) with significant differences between sampling areas $(P<0.05)$. For the sub-area of the North Sea IV-b, only 7 fish were infected by Pseudoterranova, among which only two fish had larvae in the fillets (Table 2). For the sub-area of the North Sea IV-a, 59 had Pseudoterranova larvae in overall fish, 38 in viscera and 35 in fillets with higher intensities (Table 2). For the Baltic Sea, only 6 had Pseudoterranova larvae in overall fish among them, none had Pseudoterranova in their viscera whereas the prevalence for Pseudoterranova in the fillets was $13 \%$, with variable intensities (Table 2). However, among the whole cod sampled in this area, 167 measured less than $30 \mathrm{~cm}$ and had no Pseudoterranova. For the Barents Sea, only 10 fish had Pseudoterranova larvae in overall fish, among which 7 had larvae only in the viscera and 3 only in the fillets with intensities below 10 (Table 2).

\subsubsection{Hysterothylacium spp.}

Considering the 521 whole fish sampled, the prevalence of Hysterothylacium, both larval and adult stages, was $40 \%$ (Fig. 1). Only one fish, sampled in the Barents Sea, had Hysterothylacium in the fillets, all the other infected fish only had Hysterothylacium in the viscera. Again, significant differences were observed between areas $(\mathrm{P}<0.05$, Table 2, Fig. 1).
Fig. 6. GAM smoothing curves fitted to partial effect of explanatory variables including log transformed total weight on the abundance of Anisakis in fillets + viscera ((a) total weight and (b) sampling date) and in fillets ((c) total weight). Smoothers are shown only for continuous variables with significant effects. Dashed lines represent $95 \%$ confidence intervals around the main effects. TW: total weight of the fish; Yearday: day of sampling (from 1 for the 1st of January to 365 for the 31st of December).

\subsubsection{Contracaecum spp.}

Out of 521 whole fish sampled, 159 were infected with Contracaecum larvae (31\% of prevalence, Fig. 1$)$. The vast majority of the infected fish had Contracaecum in their viscera only, with only two fish, one from the Baltic Sea and one from the Northern North Sea, containing one larva in their fillets. A similar pattern to the one observed for Hysterothylacium was obtained (Table 2, Fig. 1). Out of the 198 whole fish analyzed in the Baltic Sea, the prevalence for Contracaecum was $18 \%$, with intensities of between 1 and 96 (Table 2). However, among the 32 whole cod of commercial size and sampled in this area, the prevalence for Contracaecum was $100 \%$.

\subsection{Distribution in the fillets (Table 3)}

The precise distribution in the different parts of the fillets (right vs left, dorsal vs ventral and anterior vs posterior) was recorded for all larvae belonging to the genus Anisakis for all the sampled fish, as well as for Pseudoterranova larvae isolated from fish sampled in the Northern North Sea. Out of the 755 fish sampled in this study, 317 were infected by Anisakis in the fillets (42\% prevalence, Fig. 1). Prevalences and intensities were relatively similar between the left and the right fillets. The majority of cods infected in the fillets had parasites mainly in the ventral part of the fillet. Only in the Baltic Sea samples, out of 63 fish parasitized in the fillets, 23 had Anisakis only in the dorsal part of the fillets, leading to similar prevalence for the dorsal and the ventral part of the fillets (11 and 10\% respectively). A similar discrepancy was observed between the anterior and posterior parts of the fillets for all sampled areas, with a majority of parasites in the anterior part of the fillets.

From the 120 fish sampled in the Northern North Sea, 35 fish were infected by Pseudoterranova in their fillets. There was a similar distribution between left and right fillets, with respectively 23 and 19 fish infected. On the other hand, there was an important discrepancy for the 
Table 3

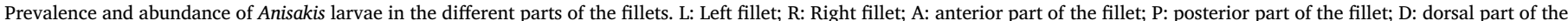
fillet; V: ventral part of the fillet.

\begin{tabular}{|c|c|c|c|c|c|c|c|c|c|}
\hline Area & $\begin{array}{l}\text { Sample } \\
\text { size }\end{array}$ & & Fillets & $\mathrm{L}$ & $\mathrm{R}$ & A & $\mathrm{P}$ & $\mathrm{D}$ & $\mathrm{V}$ \\
\hline Central & \multirow[t]{4}{*}{93} & Prevalence & 0.12 & 0.06 & 0.11 & 0.11 & 0.06 & 0.03 & 0.12 \\
\hline North & & Abundance & 1.3 & 0.55 & 0.80 & 0.83 & 0.52 & 0.23 & 1.12 \\
\hline Sea & & SD & 5.1 & 2.13 & 3.06 & 3.44 & 2.14 & 1.25 & 4.15 \\
\hline (IV-b) & & Max & 29 & 14 & 20 & 27 & 14 & 9 & 26 \\
\hline Northern & \multirow[t]{4}{*}{130} & Prevalence & 0.85 & 0.71 & 0.77 & 0.85 & 0.12 & 0.15 & 0.85 \\
\hline North & & Abundance & 6.05 & 2.88 & 3.18 & 5.94 & 0.11 & 0.23 & 5.82 \\
\hline Sea & & SD & 5.77 & 3.00 & 3.53 & 5.66 & 0.36 & 0.73 & 5.55 \\
\hline (IV-a) & & Max & 26 & 13 & 18 & 25 & 2 & 6 & 26 \\
\hline Barents & \multirow[t]{4}{*}{146} & Prevalence & 0.90 & 0.77 & 0.75 & 0.86 & 0.34 & 0.17 & 0.90 \\
\hline Sea & & Abundance & 4.84 & 2.84 & 2.01 & 4.23 & 0.61 & 0.25 & 4.60 \\
\hline \multirow[t]{2}{*}{ (I) } & & SD & 6.56 & 4.70 & 2.45 & 6.15 & 1.12 & 0.62 & 6.42 \\
\hline & & Max & 65 & 47 & 18 & 61 & 6 & 3 & 65 \\
\hline \multirow{4}{*}{$\begin{array}{l}\text { Baltic Sea } \\
\text { (III) }\end{array}$} & \multirow[t]{4}{*}{386} & Prevalence & 0.16 & 0.11 & 0.11 & 0.13 & 0.07 & 0.11 & 0.10 \\
\hline & & Abundance & 0.80 & 0.47 & 0.33 & 0.65 & 0.16 & 0.28 & 0.52 \\
\hline & & SD & 4.35 & 2.85 & 1.62 & 3.86 & 0.78 & 1.33 & 3.42 \\
\hline & & Max & 56 & 39 & 24 & 52 & 11 & 20 & 49 \\
\hline \multirow[t]{4}{*}{ All areas } & \multirow[t]{4}{*}{755} & Prevalence & 0.42 & 0.33 & 0.35 & 0.39 & 0.13 & 0.12 & 0.39 \\
\hline & & Abundance & 2.49 & 1.32 & 1.17 & 2.20 & 0.29 & 0.26 & 2.23 \\
\hline & & SD & 5.60 & 3.42 & 2.63 & 5.10 & 1.11 & 1.13 & 5.09 \\
\hline & & Max & 65 & 47 & 24 & 61 & 14 & 20 & 65 \\
\hline
\end{tabular}

distribution of Pseudoterranova larvae between the ventral and the dorsal parts of the fillets, with 33 and 7 fish respectively infected in these localizations.

\subsection{Ascaridoid molecular identification}

Six species of ascaridoid nematodes were molecularly identified from cod (Table 4), four were isolated from the fillets and the viscera (Anisakis simplex (s. s), Pseudoterranova decipiens (s. s.), Pseudoterranova krabbei, Contracaecum osculatum), one only from the fillets (Anisakis pegreffii) and the last one only from the viscera (Hysterothylacium aduncum).

One hundred and forty eight ascaridoids isolated from the fish sampled in the Baltic Sea were identified with genetic-molecular tools. Seven belonged to the species A. simplex (s.s.), 37 to $P$. decipiens (s.s.), 103 to C. osculatum and one to H. aduncum.

From 120 fish sampled in ICES area IV-a, 811 ascaridoids were isolated from the fillets and 19927 from the viscera. A subsample of 663 parasites from the fillets and 1390 from the viscera had been molecularly identified. A. simplex (s.s.) was the major species with 1919 individuals assigned to this species. It was isolated from the fillets and the viscera. Three Anisakis pegreffii were identified from the fillets of 3 fish. Sixteen Pseudoterranova decipiens (s.s.) were isolated from the whole fillets, the stomach and the liver of 9 fish. Seventy-two individuals were assigned to the species Pseudoterranova krabbei, from the fillets and the viscera of 39 fish. Forty two Hysterothylacium aduncum were identified

Table 4

Number of parasites molecularly identified from the Baltic Sea and the Northern North Sea.

\begin{tabular}{|c|c|c|c|c|}
\hline & \multicolumn{2}{|c|}{ Baltic Sea } & \multicolumn{2}{|c|}{ Northern North Sea } \\
\hline & Viscera & Fillets & Viscera & Fillets \\
\hline Anisakis simplex & & 7 & 1317 & 602 \\
\hline Anisakis pegreffii & & & & 3 \\
\hline Contracaecum osculatum & 103 & & 17 & 1 \\
\hline Hysterothylacium aduncum & 1 & & 42 & \\
\hline Pseudoterranova decipiens & & 37 & 6 & 10 \\
\hline Pseudoterranova krabbei & & & 24 & 48 \\
\hline
\end{tabular}

from 23 fish, from the viscera. Contracaecum osculatum larvae were mainly isolated from the liver. Only 2 individuals were isolated from the visceral cavity and the fillets of 2 fish.

\section{Discussion}

The present work was part of the epidemiological survey included in the EU FP7 PARASITE project (GA no. 312068). Gadus morhua was selected due to its economic importance for the European and world markets. The 755 sampled fish were exhaustively screened for ascaridoid parasites. Prevalence, intensity and abundance results were highly variable depending on several factors such as the fish length and/or weight, the geographical area, and the fishing date (Fig. 1, Table 2).

\subsection{Statistical multifactorial models}

Results from the GAM analysis led to the highlighting of several factors influencing the prevalence and/or abundance of Anisakis in overall fish and/or fillets for cod. In every analysis, sex was either not a significant factor or too many data were missing.

For the prevalence of Anisakis in viscera plus fillets and in fillets only, the studied factors (total length, residual weight of the fish, day of year and sampling area) indeed had an influence on the distribution of Anisakis in cod. However, about half of the observed variation of prevalence in the fillets was not explained by these factors. Some authors indicated some other factors that might be responsible for different distribution of anisakids in fish. Pulleiro-Potel et al. (2015) noticed that the water depth was of a relative importance on the distribution of these parasites. Marcogliese (2001) indicated several hypotheses on the reasons of anisakid variations. Among them, abiotic factors such as the water temperature was indicated as potentially responsible for the differentiate hatching of anisakid eggs. As for biotic factors, they mainly discussed from the definitive host side. However, hypothesis such as different diets could definitely apply also for the fish (Münster et al., 2015; Petric et al., 2011). Eventually, one last hypothesis was about interspecific competition. Indeed, the massive presence of other parasites, such as Contracaecum or Hysterothylacium in some fish from the Baltic or the Northern North Seas could induce a diminished availability of nutrient and/or space and thus the non-establishment of new 
anisakid larvae.

A non-negligible part of the variation in the abundance of Anisakis in viscera + fillets and in fillets only was due to studied factors (total length, residual weight of the fish, month and sampling area) and that some factors, either abiotic or biotic should also be taken into account for further studies, especially for the distribution of Anisakis in fillets (see above). Few studies indicated the descriptor of the percentage of deviance explained in the statistical analysis of data on anisakid distribution. In a study on the infection of Baltic herring by Anisakis larvae, Podolska and Horbowy (2003) found that their model, including several biotic and abiotic factors, explained $71 \%$ of the deviance for the prevalence and $25 \%$ for the intensity. Bao et al. (2015) found that the fish length, the residual condition factor, the date and the geographical location explained 71.5 and $35.8 \%$ of deviance for the number of parasites in Alosa alosa and Alosa fallax respectively. Thus, some factors, such as fish length, sampling area, and sampling month or year, have clearly been identified as influencing the distribution of Anisakis in fish. The percentage of variance explained is a helpful tool to evaluate the weight of some factors on parasite distribution. However, it should be taken into account with great cautiousness.

\subsection{Ascaridoid nematodes and geographical area}

During the present study, significant differences $(P<0.05)$ were observed between the sampling areas for all and each studied ascaridoid genus, for prevalence and abundance data in overall fish and fillets. Considering one genus at a time, some areas displayed similar distributions. For instance, the prevalence data for Anisakis, Contracaecum and Hysterothylacium were similar between the Barents Sea and the Northern North Sea. In terms of abundances, the values for the Northern North Sea were consistently above those from the Barents Sea. Thus, even though these two areas displayed some similar values, the circulations of the ascaridoids within these two ecosystems might be influenced by different factors such as the water temperature and the distributions of the first intermediate, the transport and/or the definitive hosts. The prevalence data for Pseudoterranova for these two areas were quite different with higher value for the Northern North Sea. These differences might be also due to other factors such as the weight of the fish.

Cod from the Baltic Sea presented lower prevalence of Anisakis infection in fillets (16\%), but these fish were smaller than the cod from the Barents Sea or the Northern North Sea. However, a high maximum intensity in fillets was observed (52 Anisakis/fish). These results demonstrate the importance of both parasitological indicators, prevalence and abundance, in the description of these parasite distributions. These results will also have an impact in terms of seafood safety (see 4.7).

Several authors have dealt with the distribution of ascaridoids in different geographical areas, mainly related to one country's fishing areas or to small environments such as the Gulf of St Lawrence (Boily and Marcogliese, 1995; McClelland and Marcogliese, 1994; Quiazon et al., 2011). Boily and Marcogliese (1995) suspected that either the presence of seal populations or the difference in water temperature may be factors influencing the distribution of these nematodes. PerdigueroAlonso et al. (2008) analyzed the parasite faunas of cods from 6 regions of the North-East Atlantic Ocean (Southern Baltic Sea, Northern North Sea and Central North Sea). Their prevalences for Anisakis, Contracaecum, Hysterothylacium and Pseudoterranova were quite different from the present study (Fig. 1). This could be due to several factors: 1) fillets were not analyzed; 2) sampling did not take place in the same micro-area, with for instance, their sampling in Northern North Sea in a fjord whereas ours was in the open ocean; 3) sampling did not occur at the same time of the year, spring for them and summer for our sampling in the Central North Sea; 4) possibly the size of the fish might have been different between the studies. This short comparison leads to the conclusion that it might be quite difficult to strictly compare results between studies, firstly due to the different analytical and sampling techniques, and secondly due to natural changes in host and parasite populations. The only solution would be to carry out multifactorial statistical analyses to highlight whether the differences are significant or not. This also underlines the importance of such wide-ranging studies such as the one carried out in the frame of the program PARASITE.

\subsection{Ascaridoid nematodes and fish size}

In the present study, a wide range of lengths and/or weights of fish was sampled. The total length of the fish was identified as the main studied factor influencing both the prevalence and the abundance of Anisakis in overall fish and in fillets. A noticeable result was obtained in the Baltic Sea where fish of very different sizes were analyzed. Whereas the batch of small fish (below $30 \mathrm{~g}$ ) displayed very low or no infection for Anisakis, Contracaecum and Pseudoterranova, the batch of commercial size fish displayed high prevalence and intensity values. The most obvious difference was observed for Contracaecum with a prevalence of $92 \%$ for fish above $300 \mathrm{~g}$ and $0 \%$ for fish below $30 \mathrm{~g}$ (data not shown).

Many other authors included either the length or the weight of fish as an explanatory factor of these nematode distributions and most of them found a strong positive correlation between fish size and nematode prevalence and/or abundance in different species of fish (Adroher et al., 1996; Bao et al., 2015; Brattey and Bishop, 1992; Chou et al., 2011; Levsen and Lunestad, 2010; Levsen et al., 2016; Mladineo et al., 2012; Münster et al., 2015; Zuo et al., 2016). This correlation was explained both by the accumulation of parasites during the life of the fish, considering the long life span of these parasites and by the ontogenetic shift in the feeding behavior of the fish, with the consumption of potentially more heavily infected prey by bigger fish. However, some authors found either no relationship between fish size and ascaridoid infection or a negative correlation, with the smallest fish heavily infected compared to the big ones (Horbowy et al., 2016; Rello et al., 2008; Strømnes and Andersen, 1998). These authors considered this to be the result either of an increasing mortality of large and heavily infected cod (due to a decrease of the fish condition and/or more intensive predation on these animals), or of an immune mechanism allowing the fish to eliminate the parasites (Levsen and Berland, 2011).

\subsection{Ascaridoid nematodes and seasonal distribution}

A seasonal impact on the weight of cod was observed, with lower weights obtained during the summer months (data not shown). There was no significant impact of the sampling month on the presence of Anisakis either in overall fish or in fillets. On the other hand, a significant impact of the sampling month on the number of Anisakis both in overall fish and in fillets $(\mathrm{p}<0.001)$ was observed with a peak in April-May and in August-September respectively. Controversial observations were formerly made on the impact of season on the prevalence and intensity of ascaridoid nematodes in fish. Margeirsson et al. (2007) concluded that fishing ground and time of year were the mostly influential variables on the presence of nematodes in cod, with fewer found in fish fillets between April and July in Iceland. On the other hand, a "spring rise" of Anisakis was observed in Norwegian cod with a peak of abundance in April related to a peak of phyto- and zooplankton populations (Strømnes and Andersen, 2000). Moreover, Hemmingsen et al. (1993) considered that the seasonal variationwas due to the presence of two different cod stocks at that time of the year. Thus, in this case, the seasonal variation was not a modification of the parasite population but a modification of the host population structure. This kind of effect is thus quite difficult to establish, especially for migratory host species such as cod. In the present study, cods from the Baltic Sea were sampled throughout the year. The cod stock from this area is known to be quite stationary (Mehrdana et al., 2014). However, this influence of the sampling month on the abundance of Anisakis in cod might be related to the presence of spring spawning herring stock in the Baltic waters introducing some Anisakis larvae. The difference on the 
month of the peak of abundance between overall fish and fillets could reflect an intra-vitam migration of Anisakis larvae, being first observed in the viscera, following the recent ingestion of infected fish, and a second time in the fillets. Nevertheless, more detailed studies should be carried out in the future on the other hosts (herring, sprat and zooplankton) of Anisakis in the Baltic ecosystems so as to elucidate these variations. From a wider point of view, few data are available on the distribution of ascaridoids in their first intermediate hosts (Klimpel et al., 2004; Smith and Snyder, 2005).

\subsection{Distribution in fillets}

In the present study, the distribution of ascaridoids in the fish fillets was evaluated between left and right fillets, between the dorsal and the ventral parts and between the anterior and the posterior parts of the cod fillets. No significant difference was observed between the right and the left fillets for all areas combined. However, it is noticeable that two patterns of distribution for both prevalence and abundance were present depending on the sampling area: for fish sampled in the Northern and Central North Sea, the right fillets were slightly more infected than the left, whereas the opposite was observed for fish sampled in the Barents Sea and the Baltic Sea. Some authors (Brattey and Bishop, 1992; Petrie et al., 2007) observed significant differences between the prevalence and/or abundance of ascaridoids between the right and the left fillets, always with the left fillets more infected than the right. The hypothesis was that the proximity of the fish gut with the left fillet led to an asymmetric migration of worms toward this side of the fish.

Comparing the distribution between the anterior and posterior part of the fillets, a strong difference was observed for every sampled area. The prevalence and abundance for the anterior part of the fillet were always greater than those for the posterior part. Very few studies dealt with this distribution and those authors who did analyze it obtained similar results (Novotny and Uzmann, 1960). As for the distribution between left and right, this discrepancy could be due to the proximity of the anterior part of the fillet with the visceral cavity.

Finally, the distribution of ascaridoids between the ventral and the dorsal part of the fillets was evaluated. All sampling areas included, the ventral part of the fillets was more infected by Anisakis than the dorsal part. For the Northern North Sea samples, the same result was obtained for the distribution of Pseudoterranova. The same kind of results were formerly obtained for Anisakis in several fish species such as herring (Levsen and Lunestad, 2010), cod, monkfish, mackerel, herring (Petrie et al., 2007) and seabass (Bernardi et al., 2011). Again, the shorter distance between the visceral organs and the ventral part of the fillet has been hypothesized as the main cause of this greater infection.

\subsection{Parasite molecular identification}

Until now, the only ascaridoid species described in the literature as present in G. morhua were A. simplex (s.s.), P. decipiens (s.s.), $H$. aduncum and Contracaecum sp. (Boily and Marcogliese, 1995; Brattey and Bishop, 1992; Mattiucci and Nascetti, 2008; Mattiucci et al., 1997; McClelland and Marcogliese, 1994; Strømnes and Andersen, 1998).

In the present study, the main genera identified from the cod sampled in the Baltic Sea were Pseudoterranova and Contracaecum. This result is consistent with former studies from the same areas (Mehrdana et al., 2014; Zuo et al., 2016). This distribution was correlated with the presence of seals, definitive host of these species in the Baltic Sea whereas the main definitive hosts for Anisakis are dolphins, absent from the Baltic Sea. The scarce presence of Anisakis in the Baltic cod could be due to their predation on migratory herring.

In the Northern North Sea, A. simplex (s.s.) was the major species isolated from cod. This is quite consistent with former observations on different fish species (Campbell et al., 2007; Karl and Levsen, 2011; Mattiucci et al., 2007). However, another species not previously recorded in cod has also been isolated: Anisakis pegreffii. In 2008,
Mattiucci and Nascetti (2008) reviewed the distribution of the different species of anisakid world-wide. They described $A$. pegreffii as being the major species in the Mediterranean Sea, as being present in the Austral region between $30^{\circ} \mathrm{N}$ and $55^{\circ} \mathrm{S}$ and as being restricted to the South of the Iberian Coast. This result is most probably due to the predation of these fish on migratory fish such as mackerel (Levsen et al., 2017a,b). Indeed, so far, no A. pegreffii at the adult stage has been observed in the North Sea. As for $P$. krabbei, formerly indicated as $P$. decipiens A, was previously found in G. morhua in the North East Atlantic (Paggi et al., 1991; Mattiucci and Nascetti, 2008). Our results, based on the use of a mtDNA cox2 marker, thus confirm this distribution. They even show that $P$. krabbei seems to be more widely spread than $P$. decipiens (s. s.) in this area.

The present findings both confirmed former data on the distribution of $A$. simplex (s. s.), P. decipiens (s. s.) and P. krabbei, with these three species the main ones encountered in the North East Atlantic Ocean. These results demonstrate the need to analyze a greater proportion of the isolated parasites so as to highlight the presence of minor species.

\subsection{Food safety considerations}

The zoonotic potential of Anisakis, Pseudoterranova and Contracaecum has been described by many authors (Audicana and Kennedy, 2008; Cavallero et al., 2016; Dupouy-Camet et al., 2014; Strøm et al., 2015), demonstrating the need for specific handling and checking of seafood before sale. The present work may lead to several conclusions as to the handling of potentially anisakid-infected cod batches. Some conclusions have formerly been drawn by other authors. Thus, the differential distribution of Anisakis between the ventral and the dorsal part of the fillet may facilitate an easy reduction of the parasite load by trimming the fillets (Levsen and Lunestad, 2010). In the present study, this differential distribution was observed both for Anisakis and Pseudoterranova. Some authors concluded that the presence of larvae in the visceral cavity could be a good indicator of the presence of larvae in the fillets (Karl and Levsen, 2011). This is not always true, with, for instance, Scomber scombrus displaying medium to high prevalences in the viscera but low prevalences in the fillets (Gay et al., 2012). In the present results, Anisakis prevalences were quite equivalent between viscera and fillets in all the sampling areas. Thus, our results seem to show that an inspection of the visceral cavity could lead to a prior classification of the fish and to the rejection of potentially highly infested fillets or to a special and reinforced visual control and/or trimming of these.

The present study confirms previous results as to the influence of the fish length/weight/age on the prevalence and abundance of Anisakis, with a positive correlation between these two variables. This has also been shown for Contracaecum and cod from the Baltic Sea, where only commercial size cods had high prevalence and abundance of Contracaecum in their liver. Thus, considering the higher potential of bigger fish to harbor parasites, a more intensive control and/or a systematic trimming of the fillets should be applied to bigger fish.

Moreover, the present work indicates that, at least for some areas, a subsampling to determine the infection status of fish may not be sufficient. For instance, fish from the Baltic Sea had a low prevalence but a high intensity of Anisakis in the fillets. This kind of scattered distribution may thus introduce a greater risk of the presence of parasitized fish on the market, unless each fillet is checked.

\section{Acknowledgements}

The present survey was financially supported by the European Union's 7th Framework Program for Research, Technological Development and Demonstration, project Parasite risk assessment with integrated tools in EU fish production value chains (PARASITE), Grant agreement (GA) no. 312068. The authors thank two anonymous referees for their constructive advices. 


\section{References}

Abollo, E., Gestal, C., Pascual, S., 2001. Anisakis infestation in marine fish and cephalopods from Galician waters: an updated perspective. Parasitol. Res. 87 (6), 492-499.

Adroher, F.J., Valero, A., Ruiz-Valero, J., Iglesias, L., 1996. Larval anisakids (Nematoda: Ascaridoidea) in horse mackerel (Trachurus trachurus) from the fish market in Granada (Spain). Parasitol. Res. 82 (3), 253-256.

Altschul, S.F., Madden, T.L., Schäffer, A.A., Zhang, J., Zhang, Z., Miller, W., Lipman, D.J., 1997. Gapped BLAST and PSI-BLAST: a new generation of protein database search programs. Nucleic Acids Res. 25, 3389-3402.

Audicana, M.T., Kennedy, M.W., 2008. Anisakis simplex: from obscure infectious worm to inducer of immune hypersensitivity. Clin. Microbiol. Rev. 21 (2), 360-379.

Bañon, R., Villegas-Ríos, D., Serrano, A., Mucientes, G., Arronte, J.C., 2010. Marine fishes from Galicia (NW Spain): an updated checklist. Zootaxa 2667, 1-27.

Bahlool, Q.Z., Skovgaard, A., Kania, P., Haarder, S., Buchmann, K., 2012. Microhabitat preference of Anisakis simplex in three salmonid species: immunological implications. Vet. Parasitol. 190 (3-4), 489-495.

Bao, M., Mota, M., Nachon, D.J., Antunes, C., Cobo, F., Garci, M.E., Pierce, G.J., Pascual, S., 2015. Anisakis infection in allis shad, Alosa alosa (Linnaeus, 1758), and twaite shad, Alosa fallax (Lacepede, 1803), from Western Iberian Peninsula Rivers: zoonotic and ecological implications. Parasitol. Res. 114 (6), 2143-2154.

Bao, M., Pierce, G.J., Strachan, N.J.C., Martínez, C., Fernández, R., Theodossiou, I., 2017. Consumers' attitudes and willingness to pay for Anisakis-free fish. Fish. Res (this issue).

Berland, B., 1961. Nematodes from some Norwegian marine fishes. Sarsia 2, 1-50.

Berland, B. (1991). Hysterothylacium aduncum (Nematoda) in fish. INTERNATIONAL COUNCIL FOR THE EXPLORATION OF THE SEA, fiches d'identification des maladies et parasites des poissons, crustacés et mollusques: 44 .

Bernardi, C., Gustinelli, A., Fioravanti, M.L., Caffara, M., Mattiucci, S., Cattaneo, P., 2011. Prevalence and mean intensity of Anisakis simplex (sensu stricto) in European sea bass (Dicentrarchus labrax) from Northeast Atlantic Ocean. Int. J. Food Microbiol. 148 (1), 55-59.

Boily, F., Marcogliese, D.J., 1995. Geographical variations in abundance of larval anisakine nematods in Atlantic cod (Gadus morhua) and American plaice (Hippoglossoides platessoides) from the Gulf of St. Lawrence. Can. J. Fish, Aquat. Sci. 52 (Suppl. 1), 105-115.

Brattey, J., Bishop, C.A., 1992. Larval Anisakis simplex (Nematoda: Ascaridoidea) Infection in the musculature of Atlantic Cod, Gadus morhua, from Newfoundland and Labrador. Can. J. Fish. Aquat.Sci. 49 (12), 2635-2647.

Bush, A.O., Lafferty, K.D., Lotz, J.M., Shostak, A.W., 1997. Parasitology meets ecology on its own terms: Margolis et al. revisited. J. Parasitol. 83 (4), 575-583.

Campbell, N., Cross, M.A., Chubb, J.C., Cunningham, C.O., Hatfield, E.M., MacKenzie, K., 2007. Spatial and temporal variations in parasite prevalence and infracommunity structure in herring (Clupea harengus L.) caught to the west of the British Isles and in the North and Baltic Seas: implications for fisheries science. J. Helminthol. 81 (2), $137-146$.

Cavallero, S., Nadler, S.A., Paggi, L., Barros, N.B., D'Amelio, S., 2011. Molecular characterization and phylogeny of anisakid nematodes from cetaceans from southeastern Atlantic coasts of USA, Gulf of Mexico, and Caribbean Sea. Parasitol. Res. 108 (4), 781-792.

Cavallero, S., Scribano, D., D'Amelio, S., 2016. First case report of invasive pseudoterranoviasis in Italy. Parasitol. Int. 65 (5 Pt A), 488-490.

Chou, Y.Y., Wang, C.S., Chen, H.G., Chen, H.Y., Chen, S.N., Shih, H.H., 2011. Parasitism between Anisakis simplex (Nematoda: Anisakidae) third-stage larvae and the spotted mackerel Scomber australasicus with regard to the application of stock identification. Vet. Parasitol. 177 (3-4), 324-331.

Cipriani, P., Acerra, V., Bellisario, B., Sbaraglia, G.L., Cheleschi, R., Nascetti, G., Mattiucci, S., 2016. Larval migration of the zoonotic parasite Anisakis pegreffii (Nematoda: Anisakidae) in European anchovy, Engraulis encrasicolus: implications to seafood safety. Food Control 59, 148-157.

Dupouy-Camet, J., Gay, M., Bourgau, O., Nouchi, A., Leger, E., Dei-Cas, E., 2014. Oesophageal localization: a rare complication of anisakidosis due to Pseudoterranova. Presse Med. 43 (1), 81-83.

EFSA, 2010. Scientific opinion on risk assessment of parasites in fishery products. EFSA J. 8 (4), 1543 (1591 pp.).

Gay, M., Le Fur, B., Bourgau, O., Wacogne, D., Malle, P., 2012. Localisation et détection des Anisakidae dans deux espèces de poissons: merlan (Merlangus merlangius) et maquereau (Scomber scombrus). Bull. Epidémiol. Santé Anim. Alimentation 55, $12-17$.

Hemmingsen, W., Lysne, D.A., Eidnes, T., Skorping, A., 1993. The occurrence of larval ascaridoid nematodes in wild-caught and in caged and artificially fed Atlantic cod, Gadus morhua L., in Norwegian waters. Fish. Res. 15 (4), 379-386.

Horbowy, J., Podolska, M., Nadolna-Ałtyn, K., 2016. Increasing occurrence of anisakid nematodes in the liver of cod (Gadus morhua) from the Baltic Sea: Does infection affect the condition and mortality of fish? Fish. Res. 179, 98-103.

ICES (2005). Spawning and life history information for North Atlantic cod stocks. K.B. (Ed.). Copenhagen, Denmark : 152

Køie, M., Fagerholm, H.P., 1995. The life cycle of Contracaecum osculatum (Rudolphi, 1802) sensu stricto (Nematoda, Ascaridoidea, Anisakidae) in view of experimental infections. Parasitol. Res. 81 (6), 481-489.

Karl, H., Leinemann, M., 1993. A fast and quantitative detection method for nematodes in fish fillets and fishery products. Arch. Lebensmittelhyg 44, 124-125.

Karl, H., Levsen, A., 2011. Occurrence and distribution of anisakid nematodes in Grey gurnard (Eutrigla gurnardus L.) from the North Sea. Food Control 22 (10), 1634-1638.

Klimpel, S., Palm, H.W., Ruckert, S., Piatkowski, U., 2004. The life cycle of Anisakis simplex in the norwegian deep (northern North sea). Parasitol. Res. 94 (1), 1-9.

Lagrue, C., Poulin, R., 2015. Measuring fish body condition with or without parasites: does it matter? J. Fish Biol. 87 (4), 836-847.

Levsen, A., Berland, B., 2011. Anisakis Species. Fish Parasites. CABI. CABI 385 p.

Levsen, A., Lunestad, B.T., 2010. Anisakis simplex third stage larvae in Norwegian spring spawning herring (Clupea harengus L.), with emphasis on larval distribution in the flesh. Vet. Parasitol. 171 (3-4), 247-253.

Levsen, A., Paoletti, M., Cipriani, P., Nascetti, G., Mattiucci, S., 2016. Species composition and infection dynamics of ascaridoid nematodes in Barents Sea capelin (Mallotus villosus) reflecting trophic position of fish host. Parasitol. Res. 115 (11), 4281-4291.

Levsen, A., Cipriani, P., Mattiucci, S., Gay, M., Hastie, L.C., MacKenzie, K., Pierce, G.J., Svanevik, C.S., Højgaard, D.P., Nascetti, G., González, A.F., Pascual, S., 2017a. Anisakis species composition and infection characteristics in Atlantic mackerel, Scomber scombrus, from major European fishing grounds- reflecting changing fish host distribution and migration pattern. Fish. Res (this issue).

Levsen, A., Svanevik, C.S., Cipriani, P., Mattiucci, S., Gay, M., Hastie, L.C., Pierce, G.J., Bušelić, I., Mladineo, I., Karl, H., Ostermeyer, U., Buchmann, K., Højgaard, D.P., González, A.F., Pascual, S., 2017b. A survey of zoonotic nematodes of commercial key fish species from major European fishing grounds - introducing the FP7 PARASITE exposure assessment study. Fish. Res (this issue).

Link, J.S., Bogstad, B., Sparholt, H., Lilly, G.R., 2009. Trophic role of Atlantic cod in the ecosystem. Fish Fish. 10 (1), 58-87.

Llarena-Reino, M., Piñeiro, C., Antonio, J., Outeriño, L., Vello, C., González, Á.F., Pascual, S., 2013. Optimization of the pepsin digestion method for anisakids inspection in the fishing industry. Vet. Parasitol. 191 (3-4), 276-283.

Münster, J., Klimpel, S., Fock, H.O., MacKenzie, K., Kuhn, T., 2015. Parasites as biological tags to track an ontogenetic shift in the feeding behaviour of Gadus morhua off West and East Greenland. Parasitol. Res. 114 (7), 2723-2733.

Marcogliese, D.J., 2001. Distribution and abundance of sealworm (Pseudoterranova decipiens) and other anisakid nematodes in fish and seals in the gulf of st. lawrence: potential importance of climatic conditions. The North Atlantic Marine Mammals Commission Scientific Publications 3pp. 113-128.

Margeirsson, S., Jonsson, G.R., Arason, S., Thorkelsson, G., 2007. Influencing factors on yield, gaping, bruises and nematodes in cod (Gadus morhua) fillets. J. Food Eng. 80 (2), 503-508.

Mattiucci, S., Nascetti, G., 2008. Advances and trends in the molecular systematics of anisakid nematodes, with implications for their evolutionary ecology and hostparasite co-evolutionary processes. Adv. Parasitol. 66, 47-148.

Mattiucci, S., Nascetti, G., Clanchi, R., Paggi, L., Arduino, P., Margolis, L., Brattey, J., Webb, S., D'Amelio, S., Orecchia, P., Bullini, L., 1997. Genetic and ecological data on the Anisakis simplex complex, with evidence for a new species (Nematoda, Ascaridoidea, Anisakidae). J. Parasitol. 83 (3), 401-416.

Mattiucci, S., Abaunza, P., Damiano, S., Garcia, A., Santos, M.N., Nascetti, G., 2007 Distribution of Anisakis larvae, identified by genetic markers, and their use for stock characterization of demersal and pelagic fish from European waters: an update. J. Helminthol. 81 (2), 117-127.

Mattiucci, S., Paoletti, M., Cipriani, P., Webb, S.C., Nascetti, G., 2015. Anisakis. Biology of Foodborne Parasites. In: Xiao, U.R.L., Feng, Y. (Eds.), CRC Press 520.

McClelland, G., Marcogliese, D.J., 1994. Larval anisakine nematodes as biological indicator of cod (Gadus morhua) populations in the southern gulf of St. Lawrence and on the breton shelf, Canada. Bull. Scand. Soc. Parasitol. 4 (2), 97-116.

Mehrdana, F., Bahlool, Q.Z., Skov, J., Marana, M.H., Sindberg, D., Mundeling, M., Overgaard, B.C., Korbut, R., Strøm, S.B., Kania, P.W., Buchmann, K., 2014. Occurrence of zoonotic nematodes Pseudoterranova decipiens, Contracaecum osculatum and Anisakis simplex in cod (Gadus morhua) from the Baltic Sea. Vet. Parasitol. 205 (3-4), 581-587.

Mladineo, I., Simat, V., Miletic, J., Beck, R., Poljak, V., 2012. Molecular identification and population dynamic of Anisakis pegreffii (Nematoda: Anisakidae Dujardin, 1845) isolated from the European anchovy (Engraulis encrasicolus L.) in the Adriatic Sea. Int. J. Food Microbiol. 157 (2), 224-229.

Nadler, S.A., Hudspeth, D.S., 2000. Phylogeny of the Ascaridoidea (Nematoda: ascaridida) based on three genes and morphology: hypotheses of structural and sequence evolution. J. Parasitol. 86 (2), 380-393.

Novotny, A.J., Uzmann, J.R., 1960. A statistical analysis of the distribution of a larval nematode (Anisakis sp.) in the musculature of chum salmon (Oncorhynchus ketaWalbaum). Exp. Parasitol. 10, 245-262.

Paggi, L., Nascetti, G., Cianchi, R., Orecchia, P., Mattiucci, S., D'Amelio, S., Berland, B., Brattey, J., Smith, J.W., Bullini, L., 1991. Genetic evidence for three species within Pseudoterranova decipiens (Nematoda, Ascaridida, Ascaridoidea) in the North Atlantic and Norwegian and Barents seas. Int. J. Parasitol. 21 (2), 195-212.

Perdiguero-Alonso, D., Montero, F.E., Raga, J.A., Kostadinova, A., 2008. Composition and structure of the parasite faunas of cod, Gadus morhua L. (Teleostei: Gadidae), in the North East Atlantic. Parasites Vectors 1 (1), 23.

Petric, M., Mladineo, I., Sifner, S.K., 2011. Insight into the short-finned squid Illex coindetii (Cephalopoda: Ommastrephidae) feeding ecology: is there a link between helminth parasites and food composition? J. Parasitol. 97 (1), 55-62.

Petrie, A., Wootten, R., Bruno, D., MacKenzie, K., Bron, J., 2007. A Survey of Anisakis and Pseudoterranova in Scottish Fisheries and the Efficacy of Current Detection Methods. F. P. S14008. Food Standards Agency.

Podolska, M., Horbowy, J., 2003. Infection of Baltic herring (Clupea harengus membras) with Anisakis simplex larvae, 1992-1999: a statistical analysis using generalized linear models. ICES J. Mar. Sci. 60 (1), 85-93.

Pulleiro-Potel, L., Barcala, E., Mayo-Hernández, E., Muñoz, P., 2015. Survey of anisakids in commercial teleosts from the western Mediterranean Sea: Infection rates and possible effects of environmental and ecological factors. Food Control 55, 12-17.

Quiazon, K.M., Yoshinaga, T., Ogawa, K., 2011. Distribution of Anisakis species larvae 
from fishes of the Japanese waters. Parasitol. Int. 60 (2), 223-226.

Rello, F.J., Valero, A., Adroher, F.J., 2008. Anisakid parasites of the pouting (Trisopterus luscus) from the Cantabrian Sea coast, Bay of Biscay, Spain. J. Helminthol. 82 (4), 287-291.

Smith, J.W., Snyder, J.M., 2005. New locality records for third-stage larvae of Anisakis simplex (sensu lato) (Nematoda: Ascaridoidea) in euphausiids Euphausia pacifica and Thysanoessa raschii from Prince William Sound, Alaska. Parasitol. Res. 97 (6), 539-542.

Smith, J.W., Wootten, R. (1984a). Anisakis larvae (Herringworm) (Nematoda) in fish. INTERNATIONAL COUNCIL FOR THE EXPLORATION OF THE SEA, fiches d'identification des maladies et parasites des poissons, crustacés et mollusques: 8 .

Smith, J.W., Wootten, R. (1984b). Phocascaris/Contracaecum larvae (Nematoda) in fish. INTERNATIONAL COUNCIL FOR THE EXPLORATION OF THE SEA, fiches d'identification des maladies et parasites des poissons, crustacés et mollusques: 9.

Smith, J.W., Wootten, R. (1984c). 'Pseudoterranova larvae (Codworm') (Nematoda) in fish. INTERNATIONAL COUNCIL FOR THE EXPLORATION OF THE SEA, fiches d'identification des maladies et parasites des poissons, crustacés et mollusques: 7.

Strøm, S.B., Haarder, S., Korbut, R., Mejer, H., Thamsborg, S.M., Kania, P.W., Buchmann,
K., 2015. Third-stage nematode larvae of Contracaecum osculatum from Baltic cod (Gadus morhua) elicit eosinophilic granulomatous reactions when penetrating the stomach mucosa of pigs. Parasitol. Res. 114 (3), 1217-1220.

Strømnes, E., Andersen, K., 1998. Distribution of whaleworm (Anisakis simplex, Nematoda, Ascaridoidea) L3 larvae in three species of marine fish; saithe (Pollachius virens (L.)), cod (Gadus morhua L.) and redfish (Sebastes marinus (L.)) from Norwegian waters. Parasitol. Res. 84 (4), 281-285.

Strømnes, E., Andersen, K., 2000. Spring rise of whaleworm (Anisakis simplex; Nematoda, Ascaridoidea) third-stage larvae in some fish species from Norwegian waters. Parasitol. Res. 86 (8), 619-624.

Valentini, A., Mattiucci, S., Bondanelli, P., Webb, S.C., Mignucci-Giannone, A.A., ColomLlavina, M.M., Nascetti, G., 2006. Genetic relationships among Anisakis species (Nematoda: Anisakidae) inferred from mitochondrial Cox2 sequences, and comparison with allozyme data. J. Parasitol. 92 (1), 156-166.

Zuo, S., Huwer, B., Bahlool, Q., Al-Jubury, A., Daugbjerg Christensen, N., Korbut, R., Kania, P., Buchmann, K., 2016. Host size-dependent anisakid infection in Baltic cod Gadus morhua associated with differential food preferences. Dis. Aquat. Organ. 120 (1), 69-75. 